\title{
Integration of mathematical models in marketing theory and practice
}

\author{
Ioana Olariu,AssistantProfessor PhD Student, \\ University"Vasile Alecsandri" of Bacău, Romania
}

\begin{abstract}
This article is a theoretical approach on the main mathematical models used in marketing practice. Application of general systems theory in marketing involves setting behavior assumptions as models of various processes.These models have, on the one hand, to describe the interactions between ambiance and system factors, and, secondly, to identify causal dependencies existing in these interactions. Since the models are the means by which possible solutions can be drawn consequences, they occupy a central role in the design of a system to solve a marketing problem. The model is a simplified representation which is described and conceptualized phenomena and real life situations. The purpose of a model is to facilitate understanding of the real system. Models are widely used in marketing, it takes different forms that facilitate understanding the realities of marketing.
\end{abstract}

\section{Keywords:}

Mathematical model, decision, marketing system.

\section{JEL Code: M31}

\section{Reality and abstraction in modelingprocess}

Application of general systems theory in marketing involves setting behavior assumptions as models of various processes. These models have, on the one hand, to describe the interactions between ambiance and system factors, and, secondly, to identify causal dependencies existing in these interactions. Since the models are the means by which possible solutions can be drawn consequences, they occupy a central role in the design of a system designed to solve a marketing problem. The purpose of a model is to facilitate understanding of the real system. If it is too complex, it will be difficult to understand and will facilitate the understanding of reality.

On the other hand, if the model is too simple, it will be too general and will remove too much from reality. Good modeling to combine the characteristics of two extremes to complete the models that synthesize and reproduce the essence of real structures and processes with acceptable precision and accuracy and at the same time, can be treated with relative ease. Logic models and accurate construction are useful for organizing information on events that are related to marketing activities, allowing indicate pathways and determining strategies. Models are widely used in marketing, it takes different forms that facilitate understanding of the realities of marketing.

Conceptualization modeling includes ${ }^{1}$ : (1) the perception and definition of marketing real situation, (2) identify the factors and relationships that occur in reality studied field, (3) formulate mathematical relations system, (4) solve the model by using mathematical techniques; (5) validation and model testing (6) the application of the model. Building models is a scientific process consists of a logical sequence of phases. These phases are:

\footnotetext{
${ }^{1}$ Demetrescu, M.C. (2000), Metode de analiză în marketing, Teora PublishingHouse, Bucharest, p. 28
} 
observation, formulation of a theory or hypothesis, conducting a controlled experiment, measurement and analysis of the results by comparing identical parallel processes but over which operated the experimental treatment.

Towards scientific research, aimed mainly investigate causality, building marketing models have an additional intrinsic orientation action, pursuing the knowledge acquired in solving specific problems. Modelling is based on real world situations and to recognize significant relationships between variables to get the path abstraction to representation theory.For example, a model designer can see the relationship between transport costs, the degree of satisfaction of shoppers and shopping center location, or find link between sellers and sales efforts and resulting benefits or costs of allocating funds to boost sales and achieve favorable consumer reactions.

Based on the identification of such links, designer model will become aware of logical conceptual relations that will enunciate clearly and succinctly. These relationships can then be quantified using data and information available, experiments or simulations. In this way we obtain a mathematical model to determine the background. After building a mathematical model, it can be applied to real data. Resulting feedback provides the basis for improved modeling conceptual relations perceived by quantifying changes leading to improvement and refinement of the model.

\section{Categories of models in marketing}

Characteristics on which the models can be classified are numerous. A great first classification is dividing the tangible and abstract models. Models are representations of tangible materials, models, prototypes, as in exhibitions, fairs etc. Symbolic or abstractmodels areintangible. They use ideas, concepts and abstract symbols to represent objects or quantities. Other classifications are based on the degree of formalization (verbal models, logical flow charts or mathematical models), the size of the degree of certainty (deterministic or probabilistic) or refer to time (static or dynamic models), or the scope of coverage (specific or general models) etc. Models can be built for a variety of purposes. Thus, some models are designed primarily to increase scientific knowledge. Other models aimed primarily solve specific decision problems. The most important models are those aimed primarily decision-making. But the distinction between the two categories is not absolute because the decision models inevitably contribute to widening theoretical knowledge of marketing. Models that provide guidance in the decision-making process, helping in solving marketing problems can be examined in the following order $^{2}: 1$ ) taxonomicalmodels, 2) descriptive models, 3) predictive models, 4) normative models.

1.Taxonomic models

In their simplest form, taxonomic models classify objects, events, entities or different information according to their specific characteristics that distinguish them. Taxonomic models help to simplify and improve the process of research, modeling or decision making and provide either comparing categories analyzed in order to explain the differences, nondisclosure or identification of categories in the past. Such models are those that define processes using mathematical or statistical significant market segments. Among the methods associated with the classification of the models, is listed the factor analysis, group analysis (sometimes called numerical taxonomy), multidimensional scaling, as well as joint analysis of the relationship of compensation relations for quantifying attitudes towards alternative products with more attributes and other techniques and processes ${ }^{3}$.Also from the classification models category are marketing information systems. As marketing data are

\footnotetext{
${ }^{2}$ Idem, p. 36
}

${ }^{3}$ Myers, J. G., Greyesr, S.A., Massy, W.F. (1979), The Effectiveness of Marketing's R and D for Marketing Management: An Assessment, Journal of Marketing, vol. 43, p. 17-29 
collected and stored for subsequent use by enterprise management, archives organizational problems andprompt retrieval help people find the information become increasingly important. In this regard, an important concept is the information structure that is hierarchical classification, detailed information. This classification is the expression of a model that specifiesimportant attributes of each set of data, determining the relationship between attributes of several ensembles, comprising an optimal information structure and data attributes. The problem is similar to that of group buyers in significant market segments. It is a problem of modeling the data classification. The complexity of these tasks but that the assessment information is difficult to address the current processes optimization. Simulations are used to assess the evaluation the characteristics of specific representations of information structures. In this respect has been proposed using the method of groupsanalysis from the multifactorialstatistics.

2. Descriptive models

Descriptive models aim at understanding and explaining marketing phenomena, which can be theoretical or empirical, depending on the degree to which incorporates empirical data to estimate and test parameters. Thus, marketing literature, theoretical models are found on consumer attitudes and market events, which details a number of assumptions regarding the ways in which consumers process information and make decisions to buy. Some of these models have been made in the estimates and empirical verification. Other consumption models used to explain differences in the structure of consumption expenditure and by comparing different groups of families from a sample.Many of these models are mathematical in nature, their parameters are estimated and tested methods of correlation and regression, analysis of variance and analysis of multiple discriminant. Descriptive models provide detailed and accurate representation of larger systems. The model can indicate areas where it is necessary to get some data and this information can guide the search towards experimental research or statistical studies. Explicit nature of a descriptive model provides a basis for coexistence of divergent views on the nature of the wider system. All these uses of descriptive model are related to improving problem solving because they lead to a better definition, specification and understanding of a problem.

3. Predictive models

Predictive models aim at predicting the future behavior of the system in future events. In marketing they are intended for operational purposes, namely to provide direct input into the decision making process. Thus predictive models differ from them descriptive, aiming to enhance knowledge and develop scientific research. A descriptive model can simply be predictive forecasting model parameters and inputs and subsequent use of the model to obtain an estimate of the system. Predictive models generate predictions that are necessary for planning and controlling marketing efforts of the company. Prediction models can be classified into pure prediction or extrapolation and structural.Extrapolationmodels. Purely predictive models or extrapolation are based on timebehavior marketing processes and disregard the controllable variables. One such commonly used model is that of forecasting sales. These consist forecasts of weighting different data sets on deviations between planned and actual sales. Long-term forecasts for the trend in the use forms or take into account a number of independent variables such as population, household income, etc., which in turn can be predicted using time series methods. Multiple regression is often used to estimate parameters of these models. Most stochastic models of time when choosing a brand and purchase shall be made also in this class of models. Such models for predicting change market structures are applying Markov chains and learning curves.

Systemic models of structures. Structural models explicitly introduce marketing factors and assess their effect. The structural model is designed to answer the question: what would happen if, for example, would have changed the price or any other marketing variable? The interaction between the model should be examined carefully and is necessary to test 
alternative forms of modeling ${ }^{4}$. Forecasting structural models is conditional in nature, because it depends on marketing variables. These applications of predictive models provides information and raises very significant for identifying, exploring and understanding the issues of leadership and management of marketingsystem.

4. Normative models

In contrast to descriptive and predictive models that show how a system operates and that, as it will operate in the future, normative models serve to determine system problems that must be solved. Normative mathematical models can be classified into patterns using algorithmic and enumerative optimization methods and models using heuristic methods. Another criterion for the classification of normative mathematical models namely uncertainty refers to the uncertainty of forecast reveal explicit or ignoring its results.

Optimization models. The objective of an optimization model is to maximize or minimize a result based on decision variables or controllable and uncontrollable market variables, under certain restrictions. In practice it is usually necessary to introduce intermediate stage on the significance of each result. This operation is essential when to consider preferences among different types of results.Optimization models use computer routines from which to obtain the best solution to solve the problem. And algorithmic methods are enumerated, as all acceptable alternatives are evaluated, and strictly applying the rules of a suitable algorithm leads to identifying the best alternative for crossing the decision of a finite number of steps. Linear programming techniques, quadratic and integer are algorithms. Linear programming determines maximizing a linear function of several variables decision in terms of restrictions on the values of variables. Quadratic programming or the whole number is applied in cases where the objective function involves squares and products of decision variable values or decision variables must be integervalues.Dynamic programming is an algorithm for maximizing a series of decisions over time in situations where the choice of influence strategies in a period options available or likely results in another period ${ }^{5}$. Because it provides the easiest way to minimize or maximize an amount to restrictions specified linear programming is widespread, especially in areas where you want to cut spending. With this method may be calculated best plan for achieving stated objectives, in situations where flights are limited. In the areas of designing a system or organization for solving marketing problems, these assumptions relate to forecasting system states and situations with which the system will face. Linear programming is a process linking the two sets of projections. Optimization and achieving the best response to a problem is a familiar concept for those who do mathematical calculations or who apply differential calculations to determine the rate of change of a factor depending on the modification of another factor.

Heuristic models. Heuristic models are used when the range of admissible decision alternatives is too large, so optimization by enumeration is not possible. Whereas it has to be used an organized method to search for an alternative to solve the problem, it has to resource to the use of principles that provides guidance on how to act. These principles are not conceptions of situations that a system will face, but they are straightening, guides to action, even in situations that are not anticipated in cases for which there is a formal model and analytical solution. Computer programming techniques, called heuristics, using principles of action made operational, providing search directions for future computer unnoticed or unforeseen circumstances.Compared with algorithms, heuristic procedures are more flexible and requires far fewer computations, but offers no guarantee of optimal decision alternative setting, but only that of determining good and satisfactory solution.

\footnotetext{
${ }^{4}$ Norberg, L., Arthur, G., Johnson, P., (1979), StructureandUnderstanding: SomeObservations on CurrentActivities in theFild of Structural Modeling, TehnologicalForecastingand Social Change, vol. 14, p. 278-289

${ }^{5}$ Kotler, Ph., (1970), OperationsResearchand Model Building in Marketing, Handbook of Modern Marketing, McGraw Hill, ch. 3, p. 43-61
} 


\section{Conclusions}

Logic models and accurate construction are useful for organizing information on events that are related to marketing activities, allowing indicate pathways and determining strategies. Construction of a model is subordinated to a practical purpose ${ }^{6}$. This may require the development of forecasts of future events. Sometimes these predictions are repeated, each time with other inputs to the model.

In principle, a total system designed to recurring problems will include several models of operational research: selecting the type of problem and, as such, the type of model to be chosen will be determined partly by the nature of the system, depth of the problem of leaving research system, the mathematical and methodological knowledge and experience, training and guidance to the team of analysts.

\section{Bibliography}

1. Ackoff, R.L.; Sasieni, M.W. (1975), Bazele cercetării operaţionale, TehnicaPublishingHouse, Bucharest

2. Bălan, C. (2004), Marketing - aspecte conceptuale şi operaţionale, ASE PublishingHouse, Bucharest

3. Cătoiu, I. (2004), Știința și arta modelării în marketing - dimensiuni semnificative, in Marketing, aspecte conceptuale și operationale, ASE PublishingHouse, Bucharest

4. Demetrescu, M.C., (1971), Metode cantitative in marketing, ScientificPublishingHouse, Bucharest

5. Demetrescu, M.C. (2000), Metode de analiză în marketing, TeoraPublishingHouse, Bucharest

6. Dumitrescu, M.A.; Niculescu, C. (2001), Teoria deciziei şi cercetare operaţională, NiculescuPublishingHouse, Bucharest

7. Kotler, Ph. (1988), Marketing Management, PrenticeHall Inc.

8. Kotler, Ph., (1970), OperationsResearchand Model Building in Marketing, Handbook of Modern Marketing, McGraw Hill

9. Langhoff, P. (1965), The Setting: Some Nonmetric Observations, in "Models, Measurementand Marketing”, PrenticeHall Inc.

10. Myers, J. G., Greyesr, S.A., Massy, W.F. (1979), The Effectiveness of Marketing's R and D for Marketing Management: An Assessment, Journal of Marketing, vol. 43

\footnotetext{
${ }^{6}$ Demetrescu, M.C. (2000), Metode de analiză în marketing, TeoraPublishingHouse, Bucharest, p. 36
} 